\title{
BENDA REFERENSI SEBAGAI ACUAN PENYEDERHANAAN UNTUK DETEKSI BENDA PADA KONDISI TERHALANG DENGAN METODA SUPPORT MACHINE
}

\author{
Rahmadi Kurnia*, Ratna Atika, Ikhwana Elfitri \\ Jurusan Teknik Elektro, Fakultas Teknik, Universitas Andalas \\ *Corresponding author, e-mail: rahmadi_kurnia@ft.unand.ac.id
}

\begin{abstract}
Abstrak - Sebuah benda dalam kondisi terhalang, merupakan kondisi yang sangat sulit untuk dikenali. Hal ini disebabkan keseluruhan bentuk benda tidak sempurna terlihat. Untuk aplikasi robot, tentu saja hal ini akan sangat mengganggu. Benda yang tidak sempurna terlihat akan menimbulkan kesalahan pada pengambilan keputusan bagi robot. Di sisi lain, kerumunan benda yang terlalu banyak pada lingkungan kerja robot, akan menyulitkan robot dalam mengeksekusi benda yang diinginkan oleh pengguna. Robot akan mudah mengenali benda apabila benda tersebut berada pada lingkungan yang terbatas dan tidak terlalu banyak sehingga fokus kerja nya lebih optimal. Pada benda yang terlalu banyak, probabilitas benda sasaran akan semakin kecil karena banyaknya benda-benda lain yang memungkin juga untuk menjadi kandidat sebagai benda sasaran. Untuk itu diperlukan suatu upaya menyederhanakan lingkungan kerja robot agar fokusnya bisa lebih terarah dengan cara membagi lingkungan yang terlalu ramai tersebut menjadi beberapa bagian. Salah satu patokan dalam membagi lingkungan tersebut adalah benda referensi. Penelitian ini akan menitik beratkan pada pembahasan dan peran benda referensi untuk menyederhanakan lingkungan yang terlalu ramai bagi kerja robot. Benda referensi akan ditentukan oleh robot sendiri dari fitur -fitur benda dengan parameter-parameter yang telah ditentukan. Point penting dalam penelitian ini adalah bagaimana robot bisa dengan cerdas dalam menentukan kriteria benda referensi apa yang digunakan. Sebagai penentuan kluster untuk benda referensi digunakan metoda support vector machine sebagai panduan robot menentukan kelas dan fitur benda. Tujuan akhir yang diinginkan adalah terbentuknya sistem yang sederhana dalam padangan robot, Sederhana dalam pengertian ini adalah jumlah benda maksimal 3 buah.
\end{abstract}

Kata Kunci : deteksi benda, support vector machine. benda referensi

\begin{abstract}
Object in an unobstructed condition is a very difficult condition to recognize. This is due to the overall size of imperfect objects visible. For robot applications, of course this will be very annoying. This condition will lead to errors in decision-making for robots. On the other hand, the crowd of objects that are too much in the robot work environment will complicate the robot in executing objects desired by the user. Robot will easily recognize the object if the object is in a limited environment and not too much so that the focus of his work is more optimal. On too many objects, the probability of the target object will decrease as the number of other objects also allows becoming the candidate as the target object. For that we need an effort to simplify the work environment of the robot so that the focus can be more focused by dividing the environment that is too crowded into several parts. One of the benchmarks in dividing the environment is a reference object. This research will focus on the discussion and the role of reference objects to simplify the environment that is too complicated for robot work. The reference object will be determined by the robot itself from the features with predefined parameters. An important point in this research is how robots can be as intelligent as humans think in determining what references object criteria are used. As cluster determination for reference object used support vector machine method as guide of robot determine class and feature object. The desired end goal is the formation of a simple system in the robot, Simple in this sense is the maximum number of objects 3 pieces.
\end{abstract}

Keywords : object detection, support vector machine, reference object

Copyright $(9) 2017$ JNTE. All rights reserved

\section{PENDAHULUAN}

Mendeteksi benda pada kondisi terhalang dan bergerombol adalah sebuah hal yang rumit dalam bidang object detecion terutama pada pandangan robot ( robot vision) yang bersifat dua dimensi dan tidak memiliki kedalaman pada pandangannya. Pada benda terhalang, keseluruhan tepi batas benda tidak nampak utuh, Hal ini tentu saja sangat berpengaruh pada 
penampakan bentuk dan ukuran benda tersebut. Seringkali robot akan ambigu terhadap bendabenda yang bertumpuk satu dengan yang lain karena di samping bentuk dan ukuran benda tidak jelas, juga objek yang harus dikenali terlalu banyak dan bertumpuk. Dalam keadaan terpisah, proses pengenalan dapat dilakukan salah satunya melalui proses interaksi manusia komputer, dengan cara mengenali warna dan ukuran ${ }^{[1]}$ atau fitur-fitur benda yang lain ${ }^{[2]}$ dengan berbagai metoda diantaranya dengan menggunakan karakteristik ciri benda pada diagram venn ${ }^{[3]}$. Pada kondisi benda terhalang, dapat juga dilakukan pengenalan benda berbentuk lingkaran dengan menggunakan algoritma acak $^{[4][5]}$ dengan metode rumus kelengkungan ${ }^{[6]}$ maupun RCD (Randomized Circle Detection) ${ }^{[7]}$.

Proses deteksi benda yang melibatkan interaksi manusia dan komputer telah banyak dilakukan baik menggunakan sistem dialog base $^{[8][9][10]}$ ataupun menggunakan sistem dialog melalui pengenalan suara ${ }^{[11]}$. Berdasarkan penelitian yang telah dilakukan sebelumnya, maka akan dilakukan pengembangan dalam sistem deteksi benda dengan cara membangun dialog menggunakan benda referensi untuk menyederhanakan jumlah benda sehingga sistem menjadi mudah dikenali. Komputer akan menghilangkan sebagian benda berdasarkan jawaban pengguna yang tidak masuk dalam kriteria benda yang diinginkan dengan metode ask and remove ${ }^{[12]}$. Metode ini menghilangkan benda melalui pertanyaan yang diajukan kepada pengguna dengan jawaban ya/tidak (yes/no question $)^{[12]}$. Metode ask and remove bekerja dengan cara menghilangkan benda yang tidak termasuk dari jawaban pengguna oleh komputer dan menyisakan benda yang masuk dalam kategori jawaban. Dialog yang dibangun akan menghasilkan pertanyaan yang seminimal mungkin dengan aturan sedemikian rupa, sehingga menyerupai presepsi manusia terhadap suatu benda dan melakukan konfirmasi sampai komputer dapat menyederhanakan jumlah benda sasaran seminimal mungkin.

\section{TINJAUAN PUSTAKA}

\subsection{Sistem Ruang Warna}

Pada penelitian ini sistem ruang warna yang digunakan adalah sistem ruang warna HSI (Hue Saturation Intensity) sehingga perlu dilakukan proses konversi warna dari RGB ke HSI. Pada proses pengenalan benda, lebih mudah menggunakan sistem ruang warna HSI karena kemurnian suatu warna dapat jelas terukur. Konversi nilai objek pada ruang warna RGB (Red Green Blue) ke dalam ruang warna HSI dengan menggunakan persamaan-persamaan berikut :

Komponen nilai $\mathrm{H}$ didapatkan dengan menggunakan persamaan 1 di bawah ini ${ }^{[13]}$ :

$$
H=\left\{\begin{array}{cc}
\theta & \text { Jika } B \leq G \\
360 & \text { Jika } B>G
\end{array}\right.
$$

Dengan $\theta$ didapat dengan ${ }^{[13]}$ :

$$
\theta=\cos ^{-1}\left\{\frac{\frac{1}{2}[(R-G)+(R-B)]}{\left.\left[(R-G)^{2}+(R-B)(G-B)\right)\right]^{1 / 2}}\right\}
$$

Selanjutnya untuk nilai saturasi (S) didapatkan dengan menggunakan persamaan 3 di bawah ini ${ }^{[13]}$ :

$$
S=1-\frac{3}{(R+G+B)}[\min (R, G, B)]
$$

Sedangkan nilai intensitas (I) menggunakan persamaan 4 di bawah ini ${ }^{[13]}$ :

$$
I=\frac{1}{3}(R+G+B)
$$

Berikut tabel nilai hue pada Tabel 1 di bawah ini yang digunakan untuk mendeteksi warna pada penelitian ini:

Tabel 1. Interval tiap warna pada komponen $\mathrm{HSI}^{[14]}$

\begin{tabular}{|c|c|c|}
\hline Warna & Hue & Saturation \\
\hline Merah & $0 \leq$ Hue $\leq 15$ & $41-100$ \\
\hline Hijau & $60<$ Hue $<66$ & $41-44$ \\
\hline Biru & $166<$ Hue $<175$ & $105-107$ \\
\hline Kuning & $30 \leq$ Hue $<32$ & $78-83$ \\
\hline Coklat & $4<$ Hue $<24$ & $126-130$ \\
\hline Hitam & $28<$ Hue $<54$ & $65-145$ \\
\hline Putih & $16<$ Hue $<28$ & $1-4$ \\
\hline
\end{tabular}

Warna yang tidak memenuhi ambang batas pada tabel di atas akan diset menjadi warna hitam $(\mathrm{RGB}=0)$ 


\subsection{Benda Referensi}

Ada banyak kondisi di mana bisa digunakan benda referensi. Namun yang jelas, untuk efektifitas penyederhanaan lingkungan benda, maka benda referensi haruslah terletak di tengah benda. Untuk benda referensi yang berorientasi warna, maka harus memenuhi kriteria sebagai berikut ${ }^{[12]}$ :

1. Benda referensi terletak dalam group benda.

2. Berada di pertengahan group benda.

3. Memiliki warna tunggal atau sebuah warna yang sangat dominan.

4. Secara umum memiliki warna yang mencolok.

5. Tidak boleh berukuran terlalu besar.

Contoh untuk benda referensi yang berorientasi warna, ditujukkan pada Gambar 1 di bawah ini:

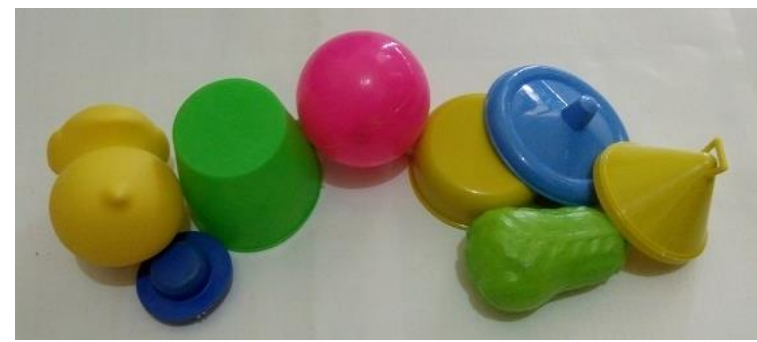

Gambar 1. Benda referensi yang berorientasi warna

Pada Gambar 1, benda yang berwarna merah adalah benda referensi karena berwarna menyolok dan terletak di pertengahan benda. Pada kondisi ini sangat mudah memisahkan benda lain untuk mencari benda sasaran dengan patokann benda yang berwarna merah di tengah tersebut.

Namun kadang kala kita tidak bisa berharap kondisi seperti Gambar 1 selalu terjadi. Kadangkadang kondisi benda yang di tengah bukanlah warna yang menyolok, tapi ukuran atau bentuknya yang menyolok dibanding benda lain di sekitarnya. Atau bisa juga warna dari benda yang ada di tengah bukanlah warna yang spesifik atau mudah diekspresikan dengan kata-kata. Hal ini bisa dilihat pada Gambar 2.

Pada Gambar 2, benda yang ada di tengah memiliki ukuran dan bentuk yang spesifik. Sedangkan warnanya, meskipun spesifik namun sulit dijelaskan atau diekspresikan dengan katakata. Pada kondisi ini yang terbaik adalah menggunakan ukuran dan bentuk sebagai referensi untuk menyederhanakan lingkungan benda dan mengurangi jumlah benda. Untuk menentukan pemilihan bentuk dan ukuran pada benda referensi, digunakan metoda support vector machine (SVM). Benda-benda referensi inilah yang akan dijadikan acuan untuk melakukan konfirmasi kepada pengguna atau user.

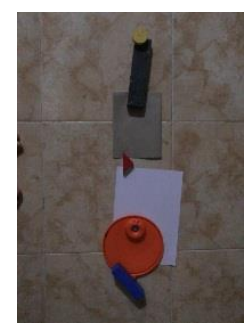

(a)

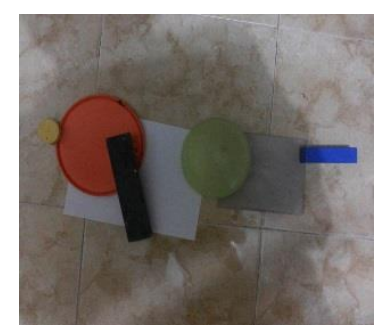

(b)
Gambar 2. Benda Referensi yang bukan berbasis warna. (a) bentuk (b) ukuran

\subsection{Ambigituas Pada Bentuk dan Ukuran}

Segmentasi citra merupakan salah satu proses atau langkah pertama dalam pengolahan citra sebelum melakukan pendeteksian benda. Segmentasi ini merupakan proses pemisahan terhadap daerah atau bagian-bagian tertentu pada citra yang memiliki homogenitas dalam segi utama yaitu tekstur, warna dan intensitas ${ }^{[12]}$. Warna-warna yang homogen ini bisa dijadikan sebuah warna yang murni untuk mempermudah proses pengenalan pada komputer atau robot. Dengan adanya proses segmentasi ini dapat dilakukan operasi terhadap benda misalnya menghitung luas dengan cara menghitung banyaknya pixel-pixel yang berwarna sama dan juga menghitung bentuknya dengan menggunakan rumus ${ }^{[12]}$ :

$$
S=4 \pi \frac{\text { luas }}{(\text { keliling })^{2}}
$$

Nilai $S$ untuk lingkaran adalah $0,9-1$. Sedangkan nilai $\mathrm{S}$ untuk persegi panjang dan bujursangkar adalah $0,7-0,9$. Sedangkan untuk segitiga nilainya $0,6-0,7$.

Adapun pelabelan diperlukan untuk membedakan benda yang satu dengan benda lainnya pada kondisi warna yang sama. Algoritma untuk menemukan komponen terkoneksi dalam sebuah citra dan menandainya disebut operasi pelabelan komponen atau component labeling ${ }^{[15]}$ 
Ada satu permasalahan dalam penentuan bentuk dan ukuran. Sebagaimana yang kita pahami, ekspresi untuk ukuran adalah besar, kecil dan sedang. Permasalahannya muncul, bagaimana menentukan sesuatu itu besar, kecil atau sedang? Berapa kalikah suatu benda itu dikatakan besar, kecil dan sedang. Di sisi lain antara ukuran dan bentuk, mana yang lebih sering orang gunakan ? Untuk menentukannya digunakanlah kluster dari pasangan pasangan ukuran dan bentuk dengan data latih. Data-data dari data latih ini akan diolah dengan menggunakan metoda support vector machine untuk mendapatkan hiperplane-nya.

\subsection{Support Vector Regression (SVR) ${ }^{[16]}$}

SVM bekerja atas prinsip structural risk minimization (SRM)dengan tujuan menemukan hyperplane terbaik yang memisahkan dua buah kelas pada input space. Prinsip dasar SVM adalah klasifikasi linear, dan selanjutnya dikembangkan agar dapat bekerja pada problem non-linear, dengan memasukkan konsep kernel trick pada ruang kerja berdimensi tinggi. Pada Gambar 3 memperlihatkan bagaimana konsep dasar dari SVM. Penyebaran data ditunjukkan oleh warna merah dan warna biru. Data berwarna merah merupakan anggota dari kelas 1 dan data berwarna biru adalah anggota dari kelas +1 . Masalah utama dari klasifikasi adalah mencari hyperplane pemisah antara kedua kelas. Hyperplane pemisah terbaik antara kedua kelas diperoleh dengan cara mengukur margin dari hyperplane dan mencari margin terbesar. Margin adalah jarak antara hyperplane tersebut dengan data terdekat dari masing-masing kelas. Data yang paling dekat dengan hyperplane disebut sebagai support vector.

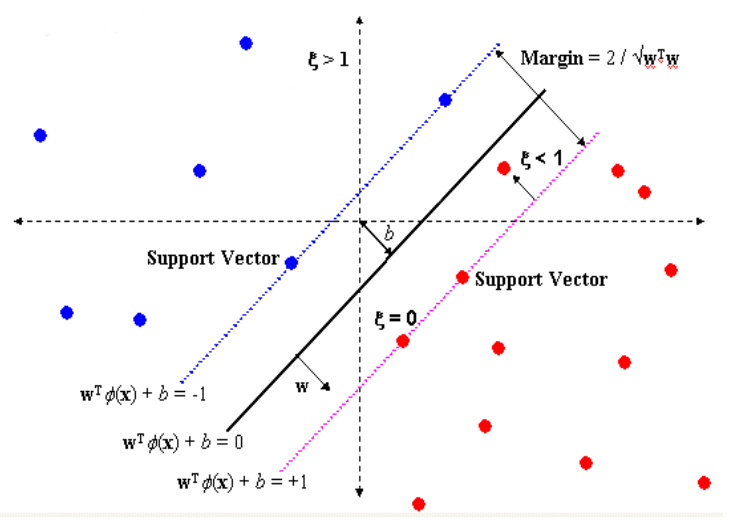

Gambar 3. Support vector machine
Ilustrasi fungsi hyperplane seperti pada Gambar 3. Terdapat fungsi berikut sebagai garis regresi:

$$
f(x)=w^{T} \phi(x)+\mathrm{b}
$$

Dimana $\phi(x)$ menunjukkan suatu titik di dalam feature space $\mathrm{F}$ hasil pemetaan $\mathrm{x}$ di dalam input space. Koefisien $w$ dan $b$ diestimasi dengan cara meminimalkan fungsi resiko (risk function) yang didefinisikan dalam persamaan:

$$
\min \frac{1}{2}\|w\|^{2}+C \frac{1}{\lambda} \sum_{i=1}^{\lambda} L_{\epsilon}\left(y_{i}, f\left(x_{i}\right)\right)
$$

dengan ketentuan:

$$
\begin{aligned}
& y_{i}-w \phi\left(x_{i}\right)-b \leq \varepsilon \\
& w \phi\left(x_{i}\right)-y_{i}+b \leq \varepsilon \\
& i=1,2, \ldots, \lambda
\end{aligned}
$$

dimana :

$$
L_{\epsilon}\left(y_{i}, f\left(x_{i}\right)\right)=\left|y_{i}-f\left(x_{i}\right)\right|-\varepsilon\left|y_{i}-f\left(x_{i}\right)\right| \geq 0
$$

Faktor $\|w\|^{2}$ adalah reguralisasi. Agar kapasitas fungsi dapat dikontrol maka fungsi harus dibuat setipis mungkin dengan cara meminimalkan $\|w\|^{2}$ Faktor kedua dalam fungsi tujuan adalah kesalahan empirik (empirical error) yang diukur dengan $\varepsilon$ insensitive lossfunction. Dengan menggunakan ide $\varepsilon$-insensitive lossfunction norm dari w harus diminimalkan agar mendapatkan generalisasi yang baik untuk fungsi regresi $f$.

Pada penelitian ini, dua klaster yang dilakukan adalah klaster bentuk dan klaster ukuran.

\section{METODOLOGI}

Berikut blok diagram proses pendeteksian benda terhalang menggunakan benda referensi dapat dijelaskan pada gambar di bawah ini :

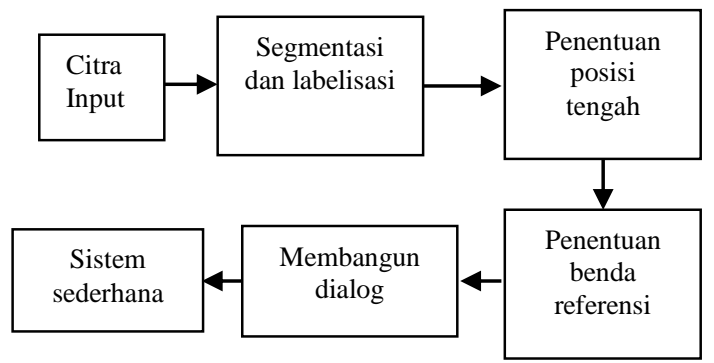

Gambar 4. Blok diagram sistem 
Pengguna menginginkan sebuah benda di antara kerumunan benda dan meminta robot mendeteksinya. Pertama-tama, kamera pada komputer mengambil frame citra input pada kerumunan benda. Kemudian melakukan proses segmentasi dengan mengubah ruang warna RGB menjadi HIS dan melakukan pelabelan. Selanjutnya dari pelabelan ini sistem menghitung jumlah benda dan menentukan posisi benda yang di tengah serta menganalisa warnanya apakah unik atau tidak. Ketika warna tidak unik, maka sistem akan menghitung luas dan ukuran benda untuk mencari benda referensi selain warna. Penentuan ini menggunakan metoda SVM (support vector machine). Selanjutnya sistem membangun dialog kepada pengguna dengan menggunakan yes/no question untuk menyederhanakan jumlah benda.

\section{HASIL DAN PEMBAHASAN}

Hasil keluaran sistem pada penelitian ini adalah menjadi sederhananya kumpulan benda yang rumit ( maksimal berjumlah 3 benda) saja melalui dialog yang efektif dan efisien antara user/pengguna dengan komputer.

Hasil penyederhanaan efektif untuk mereduksi dan menyederhanakan jumlah benda pada kondisi bergerombol dan terhalang. Ratarata jumlah pertanyaan yang diajukan oleh sistem kepada pengguna adalah 2,2 pertanyaan.

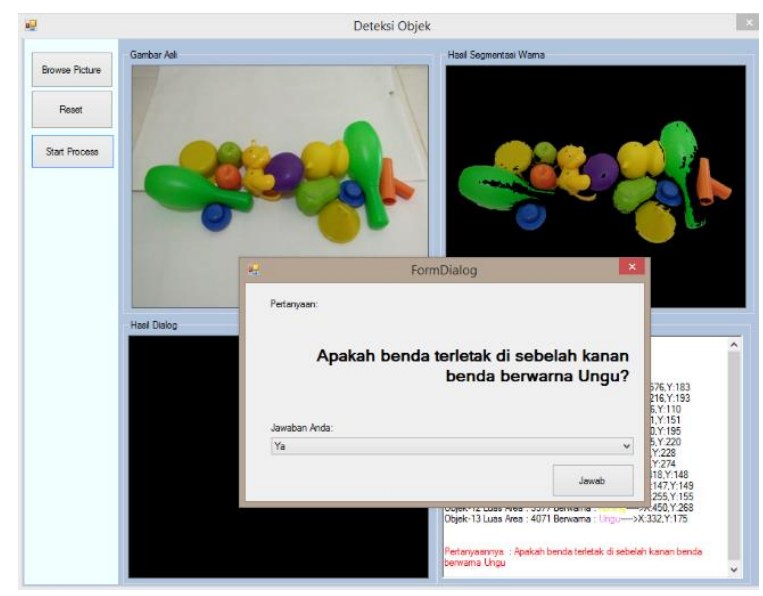

Gambar 5. Pertanyaan pertama dalam proses reduksi objek

Pada salah satu percobaan terdapat 13 benda yang saling bergerombol. Pengguna menginginkan sebuah benda berwarna hijau yang berbentuk botol yang terletak di sebelah kanan. Pada view yang nampak oleh sistem terdapat sebuah benda menyolok berwarna ungu yang berada di tengah. Maka terjadilah dialog seperti Gambar 5 dengan keterangan sebagai berikut.

Komputer : Apakah benda ada di sebelah kanan benda yang berwarna ungu?

(benda berwarna ungu adalah benda referensi yang menggunakan atribut warna benda)

Pengguna : $Y a$

(Sistem kemudian menghilangkan benda-benda di sebelah kiri benda berwarna ungu).

Komputer : Apakah benda ada disebelah kanan benda yang berwarna biru?

(benda berwarna biru adalah benda referensi yang menggunakan atribut warna benda)

Pengguna : $Y a$

(Sistem kemudian menghilangkan benda-benda di sebelah kiri benda berwarna biru).

Benda tersisa : 2 buah benda. Total Pertanyaan 2 buah.

Pada percobaan yang lain, terdapat 11 benda yang saling bergerombol. Pengguna menginginkan sebuah benda berwarna hijau yang terletak di sebelah kiri bawah. Pada view yang nampak oleh sistem terdapat sebuah benda menyolok besar yang berwarna merah yang berada di tengah. Pada kondisi ini terdapat lebih dari 1 benda berwarna merah. Sehingga warna merah ini tidak bisa dijadikan sebagai benda referensi. Dialog yang dibentuk adalah sebagai berikut:

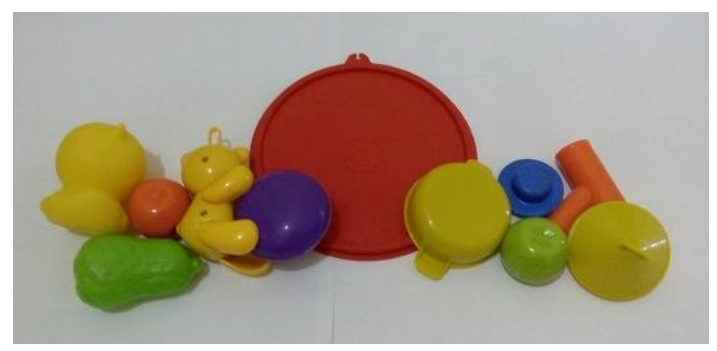

Gambar 6. Benda referensi berupa ukuran 
Komputer : Apakah benda ada di sebelah kanan benda yang besar?

(benda besar adalah benda referensi yang menggunakan atribut warna ukuran)

Pengguna : Tidak

(Sistem kemudian menghilangkan benda-benda di sebelah kanan benda yang besar).

Komputer : Apakah benda ada di sebelah kanan benda yang berbentuk lingkaran/bola?

(benda berbentuk lingkaran adalah benda referensi yang menggunakan atribut ukuran benda)

Pengguna : Tidak

(Sistem kemudian menghilangkan benda-benda di sebelah kanan benda berbentuk lingkaran).

Benda tersisa : 2 buah benda. Total pertanyaan 2 buah

Pada penelitian ini jumlah benda divariasikan dengan benda referensi yang berbeda-beda. Hasil yang diperoleh dapat ditunjukkan gambar 7 di bawah ini :

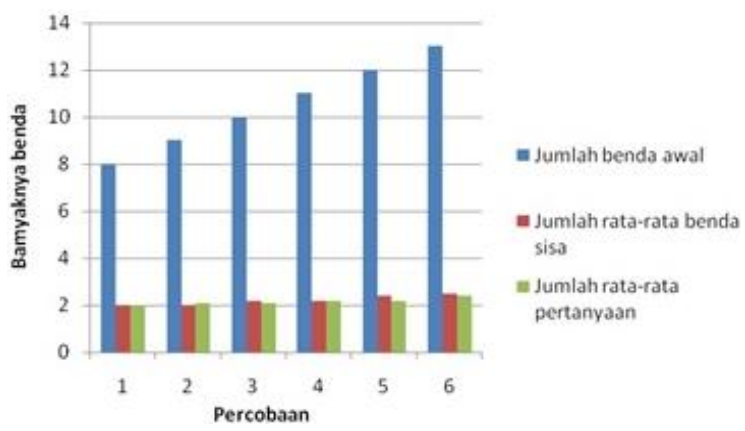

Gambar 7. Variasi jumlah benda dan jumlah pertanyaan dengan menggunakan benda referernsi

Hasil penyederhanaan efektif untuk mereduksi dan menyederhanakan jumlah benda pada kondisi bergerombol dan terhalang. Ratarata jumlah pertanyaan yang diajukan oleh sistem kepada pengguna adalah 2,2 pertanyaan.

\section{KESIMPULAN}

Dari penelitian yang telah dilakukan terlihat bagaimana benda referensi dapat bekerja dengan baik untuk mereduksi benda. Penggunaan support vektor mechine dapat memisahkan kluster bentuk dan ukuran untuk menentukan fitur yang paling sesuai untuk diajukan pertanyaan kepada pengguna. Jumlah pertanyaan terbukti efektif untuk diajukan pertanyaan kepada user. Jumlah pertanyaan terbukti efisien untuk mernyederhanakan benda sehingga menjadi sederhana dan memudahkan robot untuk melakukan deteksi benda target. Di sini terlihat bahwa sistem yang telah dirancang, teruji secara efektif dan efisien dalam melakukan langkah-langkah reduksi dan sortir benda layaknya manusia.

\section{DAFTAR PUSTAKA}

[1] Nurhadi, Silfaningrum.2008. Deteksi Obyek Berbasis Warna dan Ukuran Dengan Bantuan Interaksi KomputerManusia: Padang : Universitas Andalas.

[2] Kurnia, Rahmadi. Dialog of Features Characteristics by Using Venn Diagram for Object Detection, Proc. ICMSA, 2009.

[3] Kurnia, Rahmadi.2006.Generation of Efficient and User Friendly Queries for Helper Robots to Detect Target Object. Department of Information and Computer Sciences, Saitama University.

[4] Lianyuan Jiang, Peihe Tang, Haohao Yuan, Chungui Li, and Yalan Zhang. "Fast Randomized Algorithm for Circle Detection by Efficient Sampling”. Journal of Theoretical and Applied Information Technology Vol.48 No.2. $20^{\text {th }}$ february. (2013).

[5] Jia Li-qin, Cheng-zhang Peng, Hong-min Liu, and Zhi-heng Wang. "A Fast Randomized Circle Detection Algorithm". In Proc. $4^{\text {th }}$ International Congress on Image Signal Processing IEEE (2011).

[6] Rahadian, Asneli Putri. "Deteksi Lingkaran Pada Citra Benda Terhalang Menggunakan Metode Rumus Kelengkungan”. Padang : Universitas Andalas. (2015).

[7] Tesi, Dwi Nafia. "Deteksi Lingkaran Pada Citra Benda Terhalang Menggunakan Metode Randomized Circle Detection (RCD)". Padang : Universitas Andalas. (2015). 
[8] G. Damnati, F. Panaget, " Adding NewWords in a Spoken DialogueSystem Vocavulary Using Conceptual Information and Derived Class-based LM", Proceeding of Workshop on Automatic Speech Recognition and Understanding, 1999.

[9] Masao Takizawa, Yasushi Makihara, Nobutaka Shimada, Jun Miura and Yoshiaki Shirai, "A Service Robot with Interactive Vision- Objects Recognition Using Dialog with User". In Workshop on Language Understanding and Agents for Real World Interaction 2003.

[10] Takuya Takahashi, Satoru Nakanishi, Yoshinori Kuno and Yoshiaki Shirai,"Human Robot Intervace by Verbal and Nonverbal Behaviors". Conference: Intelligent Robots and Systems, 1998. Proceedings., 1998 IEEE/RSJ International Conference on, Volume: 2.

[11] Yasushi Makihara , Masao Takizawa , Yoshiaki Shirai, Jun Miura, Nobutaka Shimada. "Object recognition supported by user interaction for service robots". In Proceedings $16^{\text {th }}$ International Conference on Pattern Recognition Proceedings, 2002.

[12] Kurnia, Rahmadi. Deteksi Benda Berbasis Ciri Dengan Metode Dialog Komputer dan Manusia. Padang : Andalas University Press. 2015.

[13] C. L. Chien and D. C. Tseng, "Color Image Enchancment with Exact Color Model', International Journal of Innovatie Computing, Information and Control, Vol. 7, Number 12, Desember 2011, pp. 6691-6710.

[14] R. D. Kusumanto, Alan Novi Tompunu, dan Wahyu Setyo Pambudi.” Klasifikasi
Warna Menggunakan Pengolahan Model Warna HSV, Jurnal Ilmiah Elite Elektro Vol 2. No. 2 2011. Hal. 83-87

[15] Fatma, Mashiat and Jaya Sharma. "Leukemia Image Segmentation Using KMeans Clustering and HSI Color Image Segmentation". In International Journal of Computer Applications (0975 - 8887) Volume 94 - No 12, May 2014

[16] http://www.robots.ox.ac.uk/ az/lectures/ $\mathrm{ml} / \mathrm{lect} 2 . \mathrm{pdf}$

\section{Biodata Penulis}

Rahmadi Kurnia, Menyelesaikan pendidikan sarjana dari Universitas Indonesia Jurusan Elektro pada tahun 1995. Pada tahun 1998 menyelesaikan pendidikan magister dari Universitas Indonesia Jurusan Teknik Elektro Pendidikan doktor diselesaikan pada tahun 2006 dari Saitama University, Jepang. Saat ini mengajar pada Jurusan Teknik Elektro Universitas Andalas, Padang.

Ratna Atika, Menyelesaikan pendidikan sarjana dari Universitas Sriwijaya Jurusan Elektro pada tahun 2010. Saat ini sedang menempuh pendidikan magister dari Program Studi Magister Jurusan Teknik Elektro Universitas Andalas , Padang.

Ikhwana Elfitri, Menyelesaikan pendidikan sarjana dari Institut Teknologi Bandung Jurusan Elektro pada tahun 1998. Pada tahun 2002 menyelesaikan pendidikan magister dari Institut Teknologi Bandung Jurusan Teknik Elektro. Pendidikan doktor diselesaikan pada tahun 2013 dari University of Surrey, Inggris. Saat ini mengajar pada Jurusan Teknik Elektro Universitas Andalas , Padang 